Psychother. Psychosom. 1975;26:1

\title{
Editorial Statement
}

Psychotherapy and Psychosomatics, which for many years has been publishing articles in English, French and German, is changing in character. From now on it will encourage the submission of papers written in English concerning such subjects as the selection of appropriate patients and the technique and outcome of a variety of psychotherapeutic interventions of short or long duration. Case reports describing original therapeutic work will also be accepted. In addition, discussions of the etiology (whether biochemical, psychological, developmental or sociocultural) as well as of the diagnosis of psychosomatic illnesses, and of the management and treatment of psychosomatic patients will be welcome. The Journal will provide a forum for the reporting of original research on both psychotherapy and psychosomatic medicine, and will encourage the international exchange of ideas representing a variety of points of view. The Journal is the official organ of the International Federation for Medical Psychotherapy. As its vice-president and editor in chief of Psychotherapy and Psychosomatics I should like to take this opportunity to welcome all new subscribers in my sincere hope that they will use the Journal to communicate ideas to other members of our Federation.

The new editorial board has not been selected on the basis of a geographical distribution. Rather, it is composed of a group of experts in various aspects of psychotherapy and psychosomatic medicine who have gracefully accepted the responsibility of cooperating with me in the task of making the Journal interesting and stimulating, and in helping it enter an exciting phase in its history.

P.E. Peter E. Sifneos

MD

Editor in Chief 